\title{
Clinical Effect of Recalibration of the Roche Cardiac Troponin T Assay
}

\author{
David C. Gaze Paul O. Collinson \\ Department of Chemical Pathology, St. George's Healthcare NHS Trust, London, UK
}

\section{Key Words}

Troponin T recalibration - Third-generation cardiac troponin T assay

\begin{abstract}
Objective: To assess the effect of recalibration of the Roche 3rd-generation cTnT assay with recombinant human cardiac troponin T (cTnT) standards on clinical decision limits. Materials and Methods: Serum samples from 77 patients (66 \pm 16 years) admitted to the coronary care unit were assayed using the 2nd- and 3rd-generation cTnT assays. Results: There was excellent agreement ( $r=0.99$ Spearman, 95\% Cl 0.99-1.0; $p \leq 0.0001, n=153$ ) between the $2 \mathrm{nd}$ - and 3rd-generation cTnT assays across the analytical range, but there was a curvilinear relationship between values. There was concordance between the 2 nd- and 3 rd-generation cTnT values in the range from 0 to $0.2 \mu \mathrm{g} / \mathrm{l}$. Above $0.2 \mu \mathrm{g} / \mathrm{l}$, however, there were increasing but predictable differences. Conclusion: There was no statistical difference between the 2nd- and 3rdgeneration cTnT assays, demonstrated by a linear relationship below $0.2 \mu \mathrm{g} / \mathrm{l}$. This confirms that the 3rd-generation assay was calibrated to that of the $2 \mathrm{nd}$-generation assay in the range of $0-0.2 \mu \mathrm{g} / \mathrm{l}$. The detection limit and upper reference limit of normal will be unaffected by this change in calibration. A non-linear relationship at higher 2nd-generation concentrations $(0.2-25.0 \mu \mathrm{g} / \mathrm{l})$ was observed. Clinical decision limits up to $0.2 \mu \mathrm{g} / \mathrm{l}$, associated with increased cardiac risk, are unaffected by the assay calibration, but values greater than $0.2 \mu \mathrm{g} / \mathrm{l}$ are affected.
\end{abstract}

Copyright (C) 2006 S. Karger AG, Basel
(C) 2006 S. Karger AG, Basel

$1011-7571 / 06 / 0151-0029 \$ 23.50 / 0$

Fax +4161306 1234 E-Mail karger@karger.ch www.karger.com

\section{Introduction}

The cardiac troponins, cardiac troponin $\mathrm{T}(\mathrm{cTnT})$ and cardiac troponin I (cTnI), are sensitive and specific biochemical markers of myocardial injury. The large and coherent body of evidence for the diagnostic and prognostic utility of these markers has prompted the redefinition of the diagnosis of acute myocardial infarction (AMI) [1] and their inclusion in pathways for the management of unstable angina [2]. Furthermore, the National Academy of Clinical Biochemistry [3] and the International Federation of Clinical Chemistry have provided guidelines on the need for highly specific and sensitive diagnostic cardiac biomarkers, and quality specifications of troponin assays have been described [4]. However, clinical data for $\mathrm{cTnI}$ have proved more difficult for clinicians to interpret in their routine clinical practice. There is a range of cTnI assays commercially available, and the individual assays have different cut-off values and performance characteristics [5]. In contrast, cTnT is produced by one manufacturer (Roche Diagnostics, Lewes, UK), and has the largest and most comprehensive evidence base [5]. Evolution of the cTnT assay has produced improved methodological performance but with no changes to absolute values between the 1 st- and 2 nd-generation assays. This means that all of the published literature on cTnT can be directly compared, unlike the literature for cTnI where caution is required. To further improve diagnostic performance, the cTnT assay has been recalibrated using human recombinant cTnT as the calibration material to produce the 3rd-generation cTnT assay [6]. This im- 


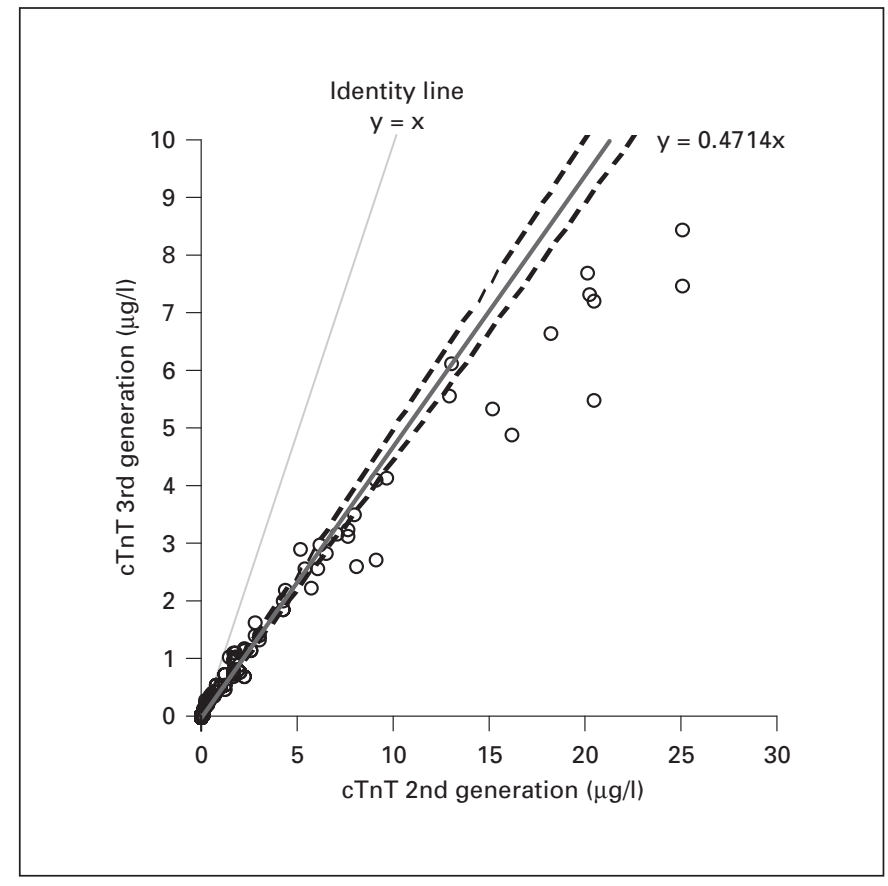

Fig. 1. Passing and Bablok plots comparing the 2nd- and 3rd-generation cTnT assays across the whole analytical range demonstrating a curvilinear response.

munoassay, however, demonstrates altered performance characteristics $[6,7]$ with better precision and thus improved clinical triage and prognostic value [7]. We evaluated the impact of this change in assay formulation on currently accepted clinical decision limits.

\section{Materials and Methods}

Serum samples were obtained using SST Vaccutainer tubes (Becton-Dickinson, Oxford, UK) from 77 patients consecutively admitted to the coronary care unit according to local ethical requirements. All were male patients, $66 \pm 16$ years old, 42 were Caucasian, 16 had a previous history of AMI and 7 had a coronary artery bypass graft. Samples were immediately and routinely analysed in the laboratory, and an aliquot was frozen and stored at $-20^{\circ} \mathrm{C}$. Following storage for a maximum of 2 weeks (within the 12 -month stability recommended by the manufacturer), samples were thawed, then assayed for cTnT by two methods - initially by the existing $\mathrm{c} \operatorname{TnT}$ method (2nd-generation assay) and then immediately re-assayed using the recalibrated assay (3rd-generation assay) in a second run, eliminating any possible freeze-thaw effects on results. Samples were assayed in two batches across two reagent lots. The Elecsys ${ }^{\circledR} 1010$ automated analyser (Roche Diagnostics) was used for all $\mathrm{cTnT}$ assay determinations according to the manufacturers' recommended methods. The 2 nd-generation cTnT assay
Table 1. Study population demographics and cardiac risk factors

Age, years
Gender
Male
Ethnicity
$\quad$ Caucasian
$\quad$ Asian
$\quad$ Afro-Carribean
Family history of IHD
Diabetes mellitus
$\quad$ NIDDM
$\quad$ IDDM
Smoker (active at admission)
Hypercholesterolaemia
Hypertension
Previous history of IHD
Previous AMI
Previous CABG

$66 \pm 16$ (range 36-101)

77

$42(55 \%)$

$16(21 \%)$

$19(25 \%)$

$36(47 \%)$

$35(45 \%)$

$26(34 \%)$

$40(52 \%)$

$58(75 \%)$

$65(84 \%)$

$56(73 \%)$

$16(21 \%)$

$7(9 \%)$

$\mathrm{CABG}=$ Coronary artery bypass graft IDDM $=$ insulin-dependent diabetes mellitus; IHD = ischaemic heart disease; NIDDM = non-insulin-dependent diabetes mellitus.

had a percentage coefficient of variation of $5.5-5.4 \%$ (at 0.32 $6.0 \mu \mathrm{g} / \mathrm{l})$ with a measuring range of $0.01-25.0 \mu \mathrm{g} / \mathrm{l}$. The manufacturers state that the analytical sensitivity is $0.01 \mu \mathrm{g} / \mathrm{l}$ and the functional sensitivity $0.05 \mu \mathrm{g} / \mathrm{l}$. The $3 \mathrm{rd}$-generation cTnT assay percent coefficient of variation was $5.8-5.7 \%$ (at $0.47-11.5 \mu \mathrm{g} / \mathrm{l}$ ) with a measuring range of $0.01-25.0 \mu \mathrm{g} / \mathrm{l}$. The manufacturers state that the analytical sensitivity is $0.01 \mu \mathrm{g} / \mathrm{l}$ and the functional sensitivity $0.03 \mu \mathrm{g} / \mathrm{l}$. Statistical analysis was by Bland-Altman, Passing and Bablok plots generated using the analyse-it ${ }^{\circledR}$ (www.analyse-it.com) add-in for Microsoft Excel ${ }^{\circledR}$, and agreement was assessed non-parametrically by Spearman rank correlation coefficient. Polynomial curve fitting was used for value comparison. Continuous variables are described as means \pm standard deviation. Categorical clinical demographics are described as actual numbers and percentages of the total population.

\section{Results}

The demographic and cardiac risk factors for the study population are summarised in table 1 . The correlation between 2 nd- and 3rd-generation assays is given in figure 1 showing excellent agreement $(r=0.99$ Spearman, 95\% confidence interval, CI, 0.99-1.0; $\mathrm{p} \leq 0.0001, \mathrm{n}=$ 153) across the whole data set; however, a curvilinear relationship was demonstrated (fig. 1) between the two assay generations across the whole analytical range. 
Sixty-three samples fell within the low-concentration band of $0-0.2 \mu \mathrm{g} / \mathrm{l}$. The $2 \mathrm{nd}-$ and $3 \mathrm{rd}$-generation assays showed no significant differences within this range $(\mathrm{r}=$ $0.97,95 \%$ CI $0.94-0.98)$. The bias was $-0.002 \mu \mathrm{g} / \mathrm{l}$, with a $95 \%$ CI from -0.005 to 0.001 (fig. 2).

\section{Discussion}

The present study demonstrates no significant difference in $\mathrm{cTnT}$ concentrations between the detection limit of 0.01 and $0.2 \mu \mathrm{g} / \mathrm{l}$, but shows a non-linear relationship at higher 2nd-generation cTnT concentrations $(>0.2 \mu \mathrm{g} / \mathrm{l})$. Current guidelines suggest that the reference range for cardiac troponin of an apparently healthy population should be at the 99th percentile and have a coefficient of variation of $10 \%$ [1]. However in reality, no commercial assay reaches this target [8]. In a study of 696 healthy adults [9], the lower limit of detection was found to be $0.01 \mu \mathrm{g} / \mathrm{l}$, the 99 th percentile was $0.01 \mu \mathrm{g} / \mathrm{l}$ with a $10 \%$ coefficient of variation at $0.03 \mu \mathrm{g} / \mathrm{l}$. The recalibration of the Elecsys cTnT assay using human recombinant cTnT rather than bovine cTnT for calibration material does not cause alterations to the proposed detection limit or the 99th percentile. A cut-off value of $0.1 \mu \mathrm{g} / \mathrm{l}$ for AMI was proposed using the 2nd-generation assay [10]. With improvements to the precision and the recent redefinition of AMI [1], a cut-off value of $0.05 \mu \mathrm{g} / 1$ is recommended for the diagnosis of AMI when using the 3rdgeneration assay [11]. Furthermore, a study comparing the 2nd-generation with the new, 3rd-generation cTnT assay in 750 patients admitted to the coronary care unit [7] demonstrated that 35\% more patients were classified as having AMI on admission with the 3rd-generation assay. The 3rd-generation assay also identified a 10\% larger low-risk group of patients with cTnT in the range from 0.01 to $0.02 \mu \mathrm{g} / 1$ who demonstrated signs of very minor myocardial necrosis [7].

The change in assay calibration has the largest impact on risk stratification cut-offs at values higher than $0.2 \mu \mathrm{g} / \mathrm{l}$. In the FRISC study [12], the risk of cardiac events (cardiac death or myocardial infarction) at 5 months in unstable coronary artery disease was assessed according to cTnT quintiles. The lowest two risk groups (cTnT $<0.06 \mu \mathrm{g} / 1,4.3 \%$ risk, and cTnT 0.06-0.18 $\mu \mathrm{g} / \mathrm{l}$, $10.5 \%$ risk) are unaffected by the assay change. The highrisk group - the three highest quintiles correspond to $0.18-0.62 \mu \mathrm{g} / \mathrm{l}$ and above (risk $16.1 \%$ ) - will now readjust to $0.18-0.38 \mu \mathrm{g} / \mathrm{l}$ and above. In this study, the greatest individual risk was seen in patients in the band from 0.62

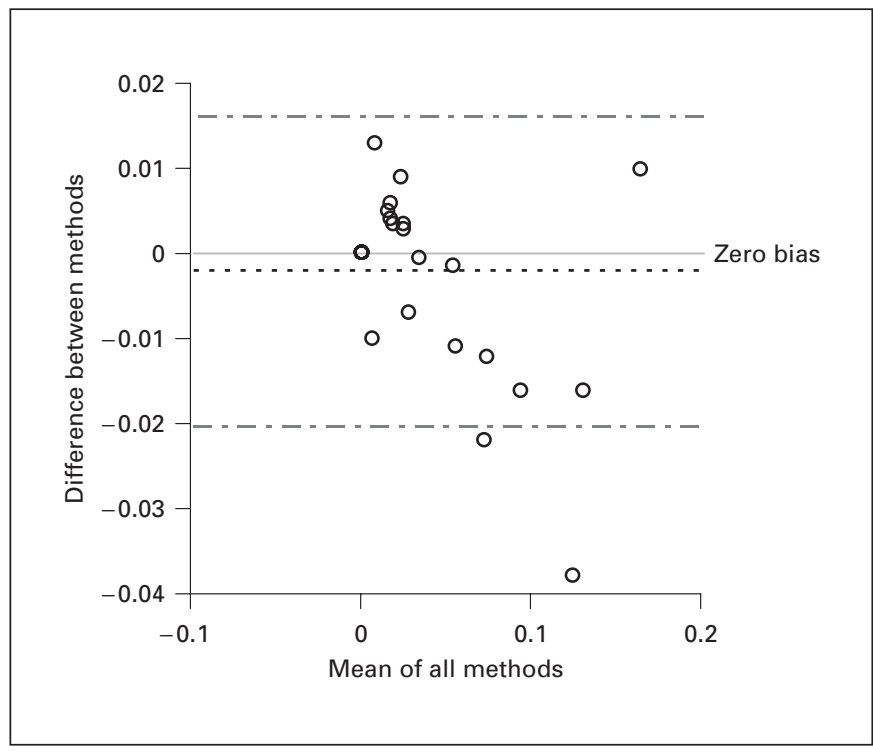

Fig. 2. Bland-Altman plot comparing the 2 nd- and 3rd-generation cTnT assays in the range from 0 to $0.2 \mu / 1$, demonstrating agreement between results.

to $2.12 \mu \mathrm{g} / 1$ (20\% risk) which now correspond to 0.38 $0.9 \mu \mathrm{g} / \mathrm{l}$ in the $3 \mathrm{rd}$-generation assay. It has been demonstrated that a $\mathrm{cTnT} \geq 2.8 \mu \mathrm{g} / \mathrm{l}$ can predict a left-ventricular ejection fraction of $<40 \%$ with $100 \%$ sensitivity and $92.9 \%$ specificity [13]. Using the new 3rd-generation assay, a cTnT of $>1.1 \mu \mathrm{g} / \mathrm{l}$ will theoretically predict a leftventricular ejection fraction of $<40 \%$ with similar sensitivity and specificity. Furthermore, the 3rd-generation assay identifies a $10 \%$ larger low-risk group with very minor $\mathrm{cTnT}(>0.01-0.02 \mu \mathrm{g} / \mathrm{l})$ elevations when using the 3rd-generation assay and is probably due to improvement in the precision at this level [6].

\section{Conclusion}

The risk classification cut-offs currently in use or proposed for cTnT in the range $0.01-0.05 \mu \mathrm{g} / 1$ are unaffected by the change in assay calibration. Previously reported values above $0.2 \mu \mathrm{g} / \mathrm{l}$ will be reduced. 


\section{References}

1 Myocardial infarction redefined - A consensus document of the Joint European Society of Cardiology/American College of Cardiology Committee for the redefinition of myocardial infarction. Eur Heart J 2000;21:1502-1513.

$\checkmark 2$ Bertrand ME, Simoons ML, Fox KA, Wallentin LC, Hamm CW, McFadden E, De Feyter PJ, Specchia G, Ruzyllo W: Management of acute coronary syndromes in patients presenting without persistent ST-segment elevation. Eur Heart J 2002;23:1809-1840.

3 Wu A, Apple F, Warshaw M (eds): National Academy of Clinical Biochemistry Standards of Laboratory Practice: Recommendations for the Use of Cardiac Markers in Coronary Artery Diseases. Washington, National Academy of Clinical Biochemistry, 1999, vol 5, 44 pp.

4 Panteghini M, Gerhardt W, Apple F, Ravkilde J, Wu A: Quality specifications for cardiac troponin assays. Clin Chem Lab Med 2001;39: 175-179.

$\checkmark 5$ Collinson PO, Boa FG, Gaze DC: Measurement of cardiac troponins. Ann Clin Biochem 2001;38:423-449.

6 Hallermayer K, Klenner D, Vogel R: Use of recombinant human cardiac troponin $\mathrm{T}$ for standardization of third generation troponin $\mathrm{T}$ methods. Scand J Clin Lab Invest 1999;59(suppl 230):128-131.
7 Jernberg T, Venge P, Lindahl B: Comparison between second and third generation troponin $\mathrm{T}$ assay in patients with symptoms suggestive of an acute coronary syndrome but without ST segment elevation. Cardiology 2003;100:29_ 35.

-8 Panteghini M, Pagani F, Yeo KTJ, Apple FS, Christenson RH, Dati F, Mair J, Ravkilde J, Wu AHB, on behalf of the Committee on Standardization of Markers of Cardiac Damage of the IFCC: Evaluation of imprecision for cardiac troponin assays at the low-range concentrations. Clin Chem 2004;50:327-332.

$>9$ Apple FS, Quist HE, Doyle PJ, Otto AP, Mukarami MA: Plasma 99th percentile reference limits for cardiac troponin and creatine kinase MB mass for use with European Society of Cardiology/American College of Cardiology consensus recommendations. Clin Chem 2003;49: 1331-1336.
10 Muller-Bardorff M, Hallermayer K, Schroder A, Ebert CH, Gerhardt W, Katus HA, et al: Improved troponin T ELISA specific for cardiac troponin $\mathrm{T}$ isoform: assay development and analytical and clinical validation. Clin Chem 1997;43:458-466.

11 Collinson PO, Stubbs PJ, Kessler AC, for the Multicentre Evaluation of Routine Immunoassay of Troponin T Study (MERIT): Multicentre evaluation of the diagnostic value of cardiac troponin T, CKMB mass and myoglobin for assessing patients with suspected acute coronary syndromes in routine clinical practice. Cardiology 2003;100:29-35.

12 Lindahl B, Toss H, Siegbahn A, Venge P, Wallentin L: Markers of myocardial damage and inflammation in relation to long-term mortality in unstable coronary artery disease. FRISC Study Group. Fragmin during instability in coronary artery disease. N Engl J Med 2000; 343:1139-1147.

13 Rao AC, Collinson PO, Rose AJ, John C, Canepa-Anson R, Joseph SP: Prospective evaluation of the role of routine cardiac troponin $\mathrm{T}$ measurement to identify left ventricular ejection fraction $<40 \%$ after first myocardial infarction. Heart 2003;89:559-560. 